\title{
A Construçáo de PEdAgogias DECOLONIAIS NOS CURRÍCULOS DAS ESCOLAS INDÍGENAS
}

\author{
ThE CONSTRUCTION OF DECOLONIAL PEDAGOGIES IN \\ INDIGENOUS SCHOOL CURRICULA
}

\begin{abstract}
José Licínio Backes
Mestre e Doutor em Educação. Docente do Programa de Pós-Graduação em Educaçáo da Universidade Católica Dom Bosco. backes@ucdb.br
\end{abstract}

Resumo: $\mathrm{O}$ artigo argumenta que as escolas indígenas estáo construindo currículos interculturais e pedagogias decoloniais. Baseia-se em teóricos da interculturalidade e numa pesquisa de campo realizada com alunos indígenas, todos com mestrado em educação. Os dados foram obtidos por meio da realização de entrevistas semiestruturadas com os indígenas no segundo semestre de 2017, contemplando as etnias Terena, Guarani e Tuyuca, bem como pela análise das dissertaçóes desses indígenas. Pela pesquisa, podese concluir que a construçấo dos currículos e das pedagogias decoloniais se baseia, sobretudo, na forte vinculação com as comunidades e na perspectiva de que a diferença entre conhecimentos não necessariamente significa hierarquização e desqualificação, mas pode significar complementaridade.

Palavras-chave: Comunidade. Currículos. Escolas Indígenas. Interculturalidade. Pedagogias Decoloniais.

Aвstract: This paper argues that Indigenous schools have been constructing intercultural curricula and decolonial pedagogies. It is based on both interculturality theorists and a field research carried out with Indigenous students, all of them with a master's degree in education. Data were obtained from both semi-structured interviews with indigenous people in the second half of 2017, with a focus on Terena, Guarani and Tuyuca ethnicities, and analysis of these subjects' dissertations. From the research, it is possible to conclude that the construction of curricula and decolonial pedagogies is mainly based on both the strong bond the Indigenous students keep with their communities and the perspective that difference between knowledges do not necessarily mean hierarchization and disqualification, but it may mean complementarity.

KeYwords: Community. Curricula. Indigenous Schools. Interculturality. Decolonial Pedagogies. 


\section{Introdução}

Os povos indígenas, desde o início da colonização, têm resistido e mantido uma luta decolonial sem trégua. Mesmo em um contexto de epistemologia abissal e fascista (SANTOS, 2007, 2008), não deixaram de lutar em favor de sua cultura, seus conhecimentos, suas identidades, suas tradiçôes. Essa epistemologia, também denominada colonial, positivista, eurocêntrica, foi central no processo de expropriação, dominação e genocídio dos povos indígenas e produziu a morte de vários conhecimentos, isto é, gerou vários epistemicídios. (SANTOS, 2007)

Para Santos (2008, p. 28), não há dúvida de que a expressão maior do fascismo epistemológico ocorreu no processo de colonização:

o fascismo epistemológico existe sob a forma de epistemicídio, cuja versão mais violenta foi a conversão forçada e a supressão dos conhecimentos não ocidentais levadas a cabo pelo colonialismo europeu e que continuam hoje sob formas nem sempre subtis.

Apesar de toda a violência, o extermínio dos conhecimentos indígenas não foi alcançado, graças à força e luta decolonial dos povos indígenas. No entanto, como o próprio autor destaca, a epistemologia fascista e, como consequência, os epistemicídios continuam no contexto atual. Porém, como veremos, os povos indígenas, com sua luta decolonial, estáo ressignificando o currículo das escolas, transformando-o em um dos instrumentos privilegiados de afirmação de suas culturas e identidades. Uma luta árdua e cotidiana, pois a escola foi introduzida nas comunidades indígenas justamente como um mecanismo decisivo da colonização, portanto, de imposição da cultura ocidental, branca, cristã, masculina, heterossexual: "a caserna fica perto da igreja, que fica ao lado da sala de aula; o quartel fica bem ao lado das 'linhas civis'." (BHABHA, 200I, p. I28)

A desconstrução desse modelo de educação e currículo colonial, para os povos indígenas, teve um marco muito importante, também em função de sua luta. Foi a Constituição de i988 que, em razáo da pressão exercida pelos povos indígenas e com o apoio de pessoas ligadas à causa indígena, incluiu o direito a uma escola indígena, bilíngue, diferenciada 
e intercultural. Essa conquista legal, obviamente, não significou o fim da escola colonial, mas representou a possibilidade concreta de os povos indígenas serem protagonistas da construção dos currículos decoloniais em suas escolas.

Com isso, várias experiências têm sido desenvolvidas, não sem tensão com o Estado, que insiste em querer impor práticas curriculares hegemônicas nos contextos indígenas, mas a luta se dá em outros termos. Ocorre algo semelhante ao que Gomes e Jesus (2013) afirmam em relação à existência da Lei 10.639/2003. Segundo eles, um dos efeitos foi dar legitimidade aos professores que já trabalhavam as questôes étnico-raciais nas escolas: se antes eles eram "acusados" de trabalharem conteúdos não previstos nos currículos, hoje eles têm legitimidade e podem usar como argumento que estão cumprindo a lei, o currículo, a LDB.

De modo semelhante, os indígenas, ao serem inquiridos pelos poderes públicos se não estão seguindo o currículo previsto pelo poder público, sobretudo quando há mudança de governo, recorrem ao argumento de que estão cumprindo a Lei Maior, a Constituição, que lhes garante o direito a uma escola diferenciada. Evidentemente, isso não resolve as tensóes nem as tentativas de colonizaçáo, mas tem sido um argumento potente para evitar a ingerência indevida (e ilegal) das políticas curriculares hegemônicas e para construir currículos decoloniais.

Embora reconheçamos que em várias escolas públicas outros currículos estão sendo praticados, privilegiar neste artigo a discussão do currículo das escolas indígenas parece-nos relevante porque são certamente experiências que mostram a capacidade de resistência, e não só no sentido de não se dobrar à cultura hegemônica ou de lutar apenas contra sua imposição, mas de continuar desenvolvendo práticas curriculares articuladas com as demandas da própria cultura e de suas identidades. Portanto, mostram a potência decolonial. Trata-se de experiências que não têm significado um isolamento ou fechamento, como se fossem identidades fixas e congeladas no tempo, mas possiblidades de construção de relaçôes interculturais baseadas no hibridismo, não como perda da identidade, mas como possibilidade de fortalecimento da própria identidade, em um processo permanente de decolonização.

Nesse sentido, trazer alguns elementos dos currículos protagonizados pelos povos submetidos há mais de cinco séculos a um processo de 
violência física e simbólica que produziu "[...] traumas sobre traumas, violências sobre violências, negação sobre negação do outro” (SKLIAR, 2003, p. II I) e mostrar que, apesar desse processo, estão construindo currículos interculturais e pedagogias decoloniais, torna-se relevante do ponto de vista epistemológico, político, social e cultural. A existência desses currículos e pedagogias é uma das formas mais visíveis da capacidade de um povo "[...] transgredir, ressignificar, hibridizar práticas, instituiçôes e formas de saber/poder, pois a escola ocidental, autoritária, assimilacionista, homogeneizante, foi ou está sendo transformada num espaço/tempo significativo para a afirmação das etnias indígenas." (BACKES, 20I4, p. I5)

\section{O currículo: um campo polissêmico}

Apesar de ser um campo marcadamente heterogêneo, incluindo concepçôes antagônicas, há alguns consensos no campo do currículo após mais de um século de estudos, dado que os primórdios dos estudos curriculares remontam ao início do século XX. Um desses consensos, bastante óbvio, é o reconhecimento de que se trata de um campo polissêmico. Essa polissemia advém do fato de o currículo não ser um dado da natureza, diferentes interpretaçóes, pois, como seres humanos criadores de cultura, instituímos diferentes sentidos para as coisas. (HALL, 1997)

Talvez uma das questóes/tensôes centrais no campo do currículo ao longo desses mais de cem anos de teorizaçóes curriculares seja o papel que ele exerce, ou, de uma perspectiva mais propositiva, qual deveria ser o papel do currículo. Apesar das várias teorizaçóes curriculares, neste artigo faremos referência a duas grandes perspectivas: uma notadamente monocultural/colonial e outra intercultural/decolonial. A primeira está invariavelmente ligada aos interesses da sociedade capitalista, que sustenta que o currículo deve ser planejado/executado com vistas ao entendimento (e ao atendimento) dos interesses da sociedade capitalista. Nessa perspectiva, não cabe ao currículo questionar a sociedade e as relaçóes sociais vigentes, haja vista que o currículo tem o papel de preparar os alunos para que se insiram nessa sociedade, segundo a retórica mais atualizada, de forma competente (formação para as competências), eficiente e flexível. 
A perspectiva monocultural/colonial, embora presente desde o período colonial, tem sua vinculação com o mundo empresarial desde o início das discussóes curriculares, mais especificamente com Tyler (PACHECO, 20I4). Desde então, apesar de passar por adaptaçóes em função dos diferentes momentos históricos, mantém a questão central, que é a de que o currículo da escola deve seguir o modelo empresarial, o que significa que deve privilegiar o conhecimento útil e objetivo, entendendo esses qualificativos como o conhecimento da cultura hegemônica (branca, ocidental, masculina, heterossexual, machista, cristã), que pode ser quantificado, mensurado, padronizado, produzindo ranqueamentos e classificações.

Como aponta Pacheco (20I4), nessa perspectiva que o autor denomina de teoria da instrução, mantendo a terminologia utilizada por Tyler, não está em questáo qual conhecimento é válido, mas como o conhecimento pode ser operacionalizado, posto que o conhecimento com o qual o currículo deve se ocupar já está definido: é o conhecimento útil e objetivo. Isso fica nítido nas diferentes formas de avaliaçáo realizadas em distintos países, incluindo o Brasil, que privilegiam os conhecimentos da língua nacional e da matemática, vistos como conhecimentos úteis, em detrimento de outros conhecimentos.

Essa perspectiva sempre foi a mais presente em diferentes países, em consonância com o desenvolvimento do capitalismo, mas no contexto atual há uma mudança no que se refere aos seus agentes principais de planejamento e avaliação. Se, no seu início, cabia aos Estados-Nação propor a política de educação com um caráter mais nacionalista, articulado com a própria fase do capitalismo, que nesse contexto tinha no Estado-Nação um ator central, nos últimos anos as políticas curriculares têm assumido um caráter mais transnacional, supranacional, por meio de um referencial global: "[...] o currículo é cada vez mais um projeto definido pelas políticas de partilha de conhecimento, com origem nos organismos transnacionais e supranacionais, tornando-o um dispositivo de regulação para a qualidade e eficiência." (PACHECO, 20I4, p. 66)

Se, na ótica dos que pensam as políticas globais, notadamente agentes econômicos que sistematicamente ignoram a produção científica do campo da educação, não há dúvidas sobre quais são os conhecimentos que devem ser contemplados, do ponto de vista das teorias interculturais/ decoloniais do currículo essa é uma questão que, além de não ter respostas 
simples, sempre terá respostas provisórias e plurais, dependendo dos contextos e das culturas nos quais os sujeitos estão imersos.

Embora as políticas globais também tragam à tona o que consideram como desafios do mundo globalizado aos quais os currículos deveráo responder, como as questôes de diversidade, multiculturalismo, inclusão, convivência entre os diferentes e tensões provocadas pela globalizaçáo cultural, cabe destacar que as propostas apresentadas divergem radicalmente das protagonizadas e buscadas pelos diferentes movimentos sociais, como os movimentos sociais indígenas do Brasil.

Como aponta Pinar (2007, p. 156), referindo-se ao contexto estadunidense, as propostas curriculares oficiais, dentro do contexto empresarial, inserem-se na lógica da homogeneização, e a diversidade não passa de uma retórica: "as tendências para a padronização curricular espelham, geralmente, as tendências para a homogeneizaçáo cultural nos Estados Unidos em geral, apesar da ponta do chapéu da retórica a favor da 'diversidade'." $\mathrm{O}$ autor defende que os currículos precisam levar em conta o local e chama atenção para o fato de que, desde o início do século XX, sobretudo com Tyler, há a pretensão de que seja possível pensar um currículo a ser aplicado em todo lugar; com isso, nas políticas curriculares, não há menção ao lugar, pois existe a ideia naturalizada de que há conhecimentos que interessam a todos.

Ainda dentro dessa lógica, aos teóricos do currículo cabe desenvolver pesquisas que tornem os professores mais eficientes na transferência de conhecimentos aos alunos. Nesse caso, as pesquisas que interessam e que tendem a receber financiamento são sobre "[...] como ensinar mais eficazmente, de modo que os alunos possam aprender mais rápido, enquanto são avaliados em exames padronizados." (PINAR, 2007, p. 320) Já que os professores, dentro dessa lógica, são vistos como "[...] habilidosos implementadores dos objetivos dos outros, algo como uma versão acadêmica do serviço postal, entregando o correio dos outros" (op.cit., p. 322), nada mais adequado do que desenvolver pesquisas que contribuam para que o professor não seja um pombo-correio nem um correio postal, mas um professor whatsapp, isto é, um professor que consegue "entregar" o conhecimento o quanto antes para seus alunos e com um custo mínimo. Isso é visto como eficácia do currículo, mas, como nos lembra Pinar (2007, p. 37), ao seguirem esse currículo as escolas não inculcam "[...] eficácia mas respei- 
tabilidade burguesa, competição, instrumentalização e monoculturalismo eurocêntrico." (PINAR, 2007, p. 37)

Mesmo que o autor esteja se referindo ao contexto estadunidense, como já apontamos, no cenário atual as políticas curriculares são pensadas por atores transnacionais e supranacionais e implementadas com poucas variaçôes nos países. Portanto, a crítica feita por essa autora aplica-se ao contexto brasileiro, sobretudo neste momento histórico, com a aprovação de uma Base Nacional Curricular Comum. Apesar de ter contado no seu início com a participação da sociedade civil e de organizaçóes representativas do campo da educação, a versão aprovada representa claramente a versão neoliberal da educação, privilegiando o homo economicus e expulsando o homo politicus, com requintes de cinismo ao incluir em seu texto demandas por justiça social: "[...] demandas tipicamente neoliberais por accountability podem se articular com demandas críticas por justiça social e, possivelmente, também com demandas conservadoras, fazendo funcionar a normatividade neoliberal." (MACEDO, 20I7, p. 5I8) Parafraseando Pinar (2007), quando afirma que a diversidade entra como retórica nas políticas curriculares e é apenas a ponta do chapéu, pode-se dizer que, na lógica da normatividade neoliberal, os apelos à justiça social não passam de retórica.

Diante disso, o que nos deve mobilizar é a retomada da dimensão política e da diferença no campo do currículo: "o compromisso com a defesa de que educação e currículo estão diretamente imbricados com a diferença como tal, assim como das conquistas - poucas ainda - dos diferentes grupos sociais que lutam por representação na esfera pública." (MACEDO, 20I7, p. 510) Os diferentes grupos sociais, organizados em movimentos sociais no Brasil, junto com muitos autores do campo do currículo, apontam que o conhecimento supostamente global, universal, transnacional e supranacional operacionalizado nos currículos por professores whatsapp, além de não contribuir para defender os interesses das minorias, se trata de uma forma de neocolonialismo, uma forma de propagar os valores eurousa-cêntricos (WALSH, 20Io). Por meio de uma retórica sofisticada, almeja justificar a riqueza de poucos em função do mérito e da competência, ao mesmo tempo que pretende explicar a miséria e a desigualdade em termos de fracasso individual e incompetência. (BAUMAN, 200I) 
Trata-se de continuar a fazer do currículo um instrumento de manutenção do capitalismo, ainda que isso continue significando condenar sujeitos, povos e culturas à miséria. Algumas dessas políticas curriculares pensadas pelos organismos internacionais referem-se à sociedade capitalista como responsável pela desigualdade mundial? Não só não se referem ao capitalismo como gerador da desigualdade, como também vão contribuindo para convencer os que vivem do trabalho que a solução está na competição (e a causa da desigualdade, na falta dela), seja para o desenvolvimento social, seja para a melhoria da qualidade da educaçáo, responsabilizando sobretudo os professores pelo fracasso da educação.

As políticas curriculares produzidas pelos organismos internacionais e aplicadas em diferentes países, incluindo o Brasil, seguem rigorosamente a lógica do mercado:

As políticas que têm definido o desenho curricular para a educação brasileira vêm sendo delineadas e implementadas desde o final dos anos de 1980, marcadamente como políticas educativas de caráter neoliberal, que passaram a ser cotidianas não somente na educação, como também na cultura, na política e, principalmente, na economia. (HYPOLITO, 2010, p.I338)

$\mathrm{Na}$ ótica dos estudos interculturais/decoloniais, elas forjam um reducionismo curricular. $\mathrm{O}$ currículo não deve ser apenas um meio de repassar informaçóes ou conhecimentos vistos por um grupo privilegiado como necessários para todos e passíveis de ser mensurados em avaliaçôes externas. Pinar (2007) aponta as consequências desastrosas que essas avaliaçôes trazem para o currículo, para os professores e para a educaçáo de modo geral, que passa a ser vista como um serviço de prestação de contas como qualquer outro serviço, sem demandar a reflexão dos professores: "os currículos orientados para os exames despromovem os professores de acadêmicos e intelectuais a técnicos a serviço do Estado. A cultura da auto-reflexão, da erudição interdisciplinar e da intelectualidade desaparece.” (PINAR, 2007, p. I9)

Essas políticas, como já destacado, trazem embutidas questóes de diversidade, inclusão, discriminação, mas o fazem como simples retórica (PINAR, 2007), em uma ótica de "tolerância" (BAUMAN, 200I), de 
um multiculturalismo liberal que não questiona as relações de poder e o processo de construção das desigualdades (McLAREN, 2000), de uma interculturalidade funcional que não pôe em xeque as assimetrias de poder. (WALSH, 2009) Aos diferentes, desiguais, excluídos, discriminados, que são vistos como problema, oferecem-se os conhecimentos que supostamente os livrarão da diferença (porque aprenderão as mesmas coisas); da desigualdade (porque aprenderão a competir para igualar-se); da exclusão (porque adquirirão as competências que o mercado requer, portanto, serão incluídos e poderão consumir as mesmas coisas); e da discriminação (porque ninguém discrimina um igual, competente, incluído, não é mesmo?).

Porém, muitos movimentos sociais, com destaque para o movimento indígena, mostram a falácia desse currículo e como ele só interessa aos grupos hegemônicos e para a manutenção de sua hegemonia. Esse currículo oficial e hegemônico não interessa aos grupos indígenas. Eles vão construindo outro currículo, um currículo intercultural/decolonial.

\section{As pedagogias decoloniais nos currículos das escolas indígenas}

As reflexóes trazidas neste momento baseiam-se em entrevistas realizadas com 12 indígenas que concluíram o mestrado em Educação e nas dissertaçóes que produziram, como parte de um projeto de pesquisa docente financiado pelo Conselho Nacional de Desenvolvimento Científico e Tecnológico (CNPq). Neste artigo, em razão do espaço disponível, faremos referência à fala de apenas um indígena de cada uma das três etnias contempladas na pesquisa, sem dizer o nome, mas apenas o gênero, sua etnia, maior formação, idade aproximada e estado onde vivem. Com essas precauçóes, mantemos o anonimato dos sujeitos. Sáo eles: Terena - aproximadamente 30 anos, sexo feminino, de Mato Grosso do Sul; Tuyuca - cerca de 50 anos, sexo masculino, do Amazonas; Guarani - próximo dos 40 anos, sexo masculino, de Mato Grosso do Sul. Todos continuam tendo uma forte vinculação com a educação escolar indígena, atuando nas escolas ou em cursos de formaçáo de professores indígenas.

Durante a realização das entrevistas esteve presente a percepção de que elas exigem uma abertura "[...] à escuta do que é inédito. Este é um 
grande desafio, pois frequentemente somos capturados em lógicas de repetição que nos fazem ouvir o que sempre ouvimos, perguntar o que sempre perguntamos e pensar o que sempre pensamos." (SOUSA, 2015, p. 87)

Uma questão que chamou atenção nas entrevistas, apontando a construção de pedagogias decoloniais, é a forte ligação que as escolas indígenas têm com suas comunidades. A construção do currículo se dá em um permanente diálogo com a comunidade, os pais, os mais velhos, as lideranças tradicionais. Nas entrevistas, todos os indígenas falam recorrentemente do papel que a comunidade exerce para a definição dos currículos das escolas. Esse vínculo pode ser traduzido pela expressão usada pela indígena Terena: "é uma corrente, é um elo. É uma coisa interminável. Tudo o que acontece na comunidade pode não começar dentro da escola, mas termina dentro dessa escola. Sempre há um elo, esse romance, esse namoro, essa paixão." Nesse sentido, pode-se dizer que essa é uma característica das escolas indígenas: seus currículos são construídos em permanente diálogo com a comunidade. Abbonizio e Ghanem (2016), ao realizarem uma pesquisa etnográfica de uma escola indígena do povo Kotiria, localizada no município de São Gabriel da Cachoeira, no estado do Amazonas, concluíram que a comunidade tem papel central na definição dos rumos da escola: "foi a comunidade que entendeu que fazia sentido e era preferível considerar como saberes escolares também os saberes das pessoas daquele lugar. Foram eles, portanto, que idealizaram uma escola para si, uma escola própria, específica." (ABBONIZIO; GHANEM, 20I6, p. 894)

Esse vínculo é fundamental para a construção de pedagogias decoloniais. Os professores indígenas, apesar de serem reconhecidos como lideranças em suas comunidades, não decidem sozinhos o currículo da escola. Este é sistematicamente discutido por cada comunidade, com a participação de todos, com destaque para os mais velhos, sujeitos centrais para que os currículos possam trabalhar os conhecimentos tradicionais do povo e possam se dar na perspectiva de uma pedagogia decolonial. Além disso, observa-se que todas as dissertações realizadas pelos indígenas entrevistados têm como foco central uma temática relacionada às suas comunidades, ao seu povo: a educação escolar indígena, a língua indígena, os saberes matemáticos indígenas, os saberes tradicionais, a interculturalidade, os conhecimentos indígenas, a cosmovisão indígena. São justamente essa força e resistência ao que a cultura ocidental procura impor desde o século 
XVI que fazem com que eles continuem existindo como povos: "[...] os índios que 'sobreviveram' o fizeram exatamente por terem mantido a sua diferença cultural e não terem se diluído no caldeirão da sociedade nacional." (CAMARGO; ALBUQUERQUE, 2003, p. 343)

Nesse sentido, pode-se dizer que, para os indígenas, as comunidades continuam sendo comunidades éticas (BAUMAN, 2003). Segundo esse autor, no contexto atual, caracterizado por ele como modernidade líquida (BAUMAN, 200I), cada vez mais surgem comunidades estéticas. Estas, diferentemente das comunidades éticas, não postulam vínculos coletivos, não têm compromissos com o outro nem supóem um laço de união permanente. As comunidades estéticas são a expressão da sociedade líquida, onde os sujeitos são vistos como indivíduos que só podem contar com as suas forças individuais para fazerem suas conquistas; sendo assim, tanto o sucesso quanto o fracasso são de exclusiva responsabilidade do indivíduo. As comunidades estéticas são comunidades de indivíduos que só têm em comum o fato de terem os mesmos problemas e de acreditarem que a solução desses problemas passa exclusivamente pela dimensão individual: "uma coisa que a comunidade estética definitivamente não faz é tecer entre seus membros uma rede de responsabilidades éticas e, portanto, de compromissos a longo prazo." (BAUMAN, 2003, p. 67)

Já as comunidades éticas são aquelas que postulam que a solução de problemas, necessariamente, se dá pelo cuidado mútuo: "uma comunidade de interesse e responsabilidade em relação aos direitos iguais de sermos humanos e igual capacidade de agirmos em defesa desses direitos." (op. cit., p. 134) Essas comunidades éticas efetivamente continuam sendo uma das características dos povos indígenas: elas se mantêm em torno de seus conhecimentos, identidades, tradiçôes, cosmovisôes, suas culturas, e têm sido centrais para a construção dos currículos das escolas indígenas.

Contudo, a construção dos currículos dessas escolas dá-se também no diálogo com os conhecimentos não-indígenas, que não são vistos como superiores, mas como necessários no contexto atual para que os indígenas possam melhor negociar com a cultura do entorno - não para dobrar-se a ela, mas para afirmar a sua; não para seguir uma pedagogia colonial, mas para construir pedagogias decoloniais. Isso ajuda a explicar a procura dos indígenas pela universidade e, mais recentemente, também pela pósgraduação stricto sensu. É interessante observar, nas entrevistas realizadas 
com os indígenas, que não se percebem hierarquizaçóes entre os conhecimentos, mas complementaridade. Pode-se dizer, utilizando a expressão de Santos (2007), que mesmo após séculos de predomínio da epistemologia abissal os indígenas não se dobraram a ela. Ao contrário, eles colocam os conhecimentos indígenas no mesmo patamar dos conhecimentos ocidentais, eles desenvolvem pedagogias decoloniais.

Pode-se dizer que, talvez por essa razão, falar em educação intercultural, escola intercultural e currículo intercultural faça tanto sentido para eles, pois, a rigor, estão lidando com conhecimentos diferentes, mas não em termos de superioridade ou inferioridade. Utilizando-se o conceito de hibridismo de Laclau (20II, p. I05), é possível dizer que eles transformam o encontro com conhecimentos diferentes em uma possiblidade de fortalecer a sua própria cultura e identidade, pois a "[...] hibridização não significa necessariamente declínio decorrente de uma perda de identidade. Também pode significar o fortalecimento das identidades existentes pela abertura de novas possibilidades." Os indígenas reconhecem que, em algumas situaçóes, os conhecimentos ocidentais podem ser mais apropriados para resolver um determinado problema, mas náo os colocam como superiores aos seus. $\mathrm{O}$ uso dos conhecimentos ocidentais não póe em xeque o conhecimento tradicional do seu povo, apenas mostra que há conhecimentos diferentes e, principalmente, que o conhecimento tradicional muitas vezes não dá conta de problemas criados pelo conhecimento ocidental, sendo necessário recorrer a este último.

A experiência contada pelo indígena Guarani mostra bem essa relação entre os conhecimentos, uma relação que não passa pela hierarquização nem pela desclassificação, mas pela complementaridade - trata-se de uma relação que se dá em uma lógica decolonial. Ele relata que um dos problemas de sua comunidade atualmente é a contaminação da água em decorrência do uso de agrotóxicos em terras não-indígenas. Segundo ele, os saberes tradicionais não dão conta de resolver esse problema. Nesse caso, é necessário recorrer aos saberes ocidentais para saber se a água é contaminada e como tratá-la. Continuando sua explicação, ele mostra que os ocidentais poderiam aprender a cuidar da natureza, a viver sem destruí-la, a não viver para consumir, a não contaminar a água para depois ter que limpá-la. Os ocidentais poderiam aprender a ver-se como parte da natureza, e não como os dominadores, os destruidores. Para ele, é possível apren- 
der algumas coisas com os ocidentais, e os ocidentais também poderiam aprender algumas coisas com os indígenas, mas reconhece que o ocidental não quer aceitar que pode aprender com eles. Nas palavras do indígena Guarani: "e aí você vai trabalhar a água, o que é a água para o Guarani. A contaminação da água. Quem vai entender essa contaminação é outro conhecimento. Então, eles vão se complementando um ao outro, no sentido de trazer a soluçáo, nesse caso, para a comunidade." Da mesma forma, ao narrar como o seu povo e como a física ocidental explica a existência dos raios, ele afirma: "eu acho muito interessante. Um complementa o outro. Você não nega. Eles estão aí, e não se nega nenhum. Não se diz 'esse está errado', 'esse está certo'. Os dois se complementam."

Embora neste texto façamos referência a apenas algumas falas, saliente-se que, em todas as entrevistas realizadas, não identificamos momentos em que os indígenas tenham classificado os conhecimentos como inferiores e superiores. A perspectiva que assumem é a de que são conhecimentos que podem complementar-se, em um processo de hibridização: "o hibridismo permite que outros saberes 'negados' se infiltrem no discurso dominante e tornem estranha a base de sua autoridade - suas regras de reconhecimento." (BHABHA, 200I, p. I65)

Como já mencionado, isso não significa, em hipótese alguma, que os indígenas não tenham ciência de que convivem cotidianamente com tentativas de epistemicídios por um conhecimento colonial e de que seus conhecimentos têm sido considerados, pela epistemologia fascista e abissal, como insignificantes, não sendo reconhecidos nem considerados legítimos. Porém, isso não faz com que os vejam assim. $\mathrm{O}$ indígena da etnia Tuyuca contou o que falaria em uma palestra em uma universidade. Disse que iria começar sua palestra com um questionamento: "estamos aqui numa universidade, lugar de educação superior. Educação superior que costuma dizer que nosso conhecimento é inferior. Superior a quê? Eu vos pergunto: como um conhecimento que há milhares de anos tem garantido a vida de seus povos pode ser considerado inferior?”

Observamos de forma efetiva o questionamento radical da epistemologia abissal e fascista. Trata-se de um questionamento que traz as marcas da pedagogia decolonial. Diferentemente da epistemologia fascista, que se afirma como superior, impondo-se pela violência e pelo grau de destruição que é capaz de provocar (a superioridade muitas vezes é diretamente 
proporcional à capacidade de destruir vidas, como nos processos coloniais, em que milhôes foram dizimados com o auxílio do conhecimento científico ocidental disponível na época), o indígena Tuyuca mostra que um conhecimento possui validade na medida em que ele consegue manter a vida de um povo e a integridade da natureza. Nesse sentido, pode-se dizer que o indígena Tuyuca revela "[...] uma ruptura radical com as formas de pensamento e ação da modernidade ocidental” (SANTOS, 2007, p. 85) e mostra que "[...] a resistência política deve ter como postulado a resistência epistemológica." (op.cit., p. 83)

A fala do indígena Tuyuca e dos demais indígenas entrevistados corrobora o que evidencia Santos (2007) quando aponta que os indígenas da América são os que mais podem contribuir com suas concepçôes e práticas para a construção de outro mundo. Segundo o autor, neles é possível perceber aquilo que ele denomina 'pensamento pós-abissal', ou seja, um pensamento que não cria um abismo entre os modos de pensar diferentes, que não desperdiça experiências, que não supõe a existência de um pensamento único, enfim, que não se move na lógica do fascismo epistemológico.

Portanto, a construção dos currículos das escolas indígenas baseiase não em uma epistemologia abissal que, "[...] mais do que não conhecer os outros saberes, recusa reconhecer sequer que eles existam” (SANTOS, 2008, p. 27), mas na existência de várias epistemologias - baseia-se em pedagogias decoloniais. É assim que a construção desses currículos e das pedagogias decoloniais, recorrendo a Walsh (2010), se dá por uma luta que atua, no mínimo, em três dimensóes: intercultural, interepistêmica e, obviamente, também decolonial. Essas três dimensóes, a rigor, mesclam-se, encontram-se, entrecruzam-se, enfim, estão articuladas. Pensar na articulação dessas dimensões tem "[...] a grande vantagem de nos possibilitar pensar como práticas específicas (articuladas em torno de contradiçóes que não surgem da mesma forma, no mesmo momento e no mesmo ponto) podem, todavia, ser pensadas conjuntamente." (HALL, 2003, p. I52)

Com a dimensão intercultural, os indígenas questionam a pedagogia colonial, o currículo nacional, o currículo oficial e os conhecimentos ocidentais, não apenas com o intuito de incluir marginalmente a cultura e o conhecimento indígena. $O$ processo se dá no sentido de colocar os conhecimentos e a cultura indígenas como constitutivos, como centrais, criando outros currículos, currículos voltados para as suas comunidades - não pen- 
sados para elas de fora ou por alguns, mas pensados com as comunidades e pelas comunidades. Com isso, as formas de pensar, conhecer, ser, estar e conviver do grupo étnico são sistematicamente afirmadas (WALSH, 20ıo). Os indígenas, com suas pedagogias decoloniais, ensinam-nos a refletir "[...] sobre outros tempos e espaços, sobre o que significa viver, sobre como é possível construir outras narrativas identitárias. Instigam-nos também a pensar em como resistir, subverter, ressignificar práticas de colonização e de subordinação." (BACKES; NASCIMENTO, 20I , p. 26) Ensinam-nos como é possível construir outros currículos e outras pedagogias.

Quanto à dimensão interepistêmica, os indígenas transgridem os marcos epistemológicos euro-usa-cêntricos, não seguem a epistemologia abissal, e mostram que os conhecimentos não precisam ser necessariamente hierarquizados e desqualificados em função da sua diferença, mas que podem ser complementares. Os indígenas notadamente movem-se com outras pedagogias, outros modos de pensar e produzir conhecimentos. Não se pautam em uma única lógica, muito menos na lógica da dominação e da exclusão da diferença, mas na ideia de que conhecimento verdadeiro é aquele que é a favor da vida, que garante a vida, a cultura, a identidade de um povo. Para eles, os conhecimentos resultam de diferentes lógicas: lógicas orais, lógica dos rezadores, dos mais velhos, da espiritualidade, da cultura e também das lógicas ocidentais. As lógicas ocidentais, apesar de seu ímpeto fascista, são decolonizadas pelos indígenas e vistas como mais uma possibilidade de construir conhecimentos. Esses conhecimentos, ao serem apropriados pela comunidade indígena, passam a ser um elemento a favor da própria comunidade. Há uma pluralidade de conhecimentos, lógicas e racionalidades, e os indígenas constroem uma pedagogia das relaçôes, articulaçóes e convergências, mesmo no contexto da hegemonia da epistemologia fascista.

Quanto à dimensão decolonial propriamente dita, os indígenas sabem da importância de seus conhecimentos, ao mesmo tempo que sabem que a cultura ocidental e sua epistemologia hegemônica insistem em desqualificá-los. Porém, eles estão sempre desafiando a matriz colonial de poder e de dominação presentes no currículo hegemônico e constroem outros currículos, constroem pedagogias decoloniais. Nesse sentido, eles mostram que: a) é possível construir pedagogias decoloniais voltadas para os conhecimentos do próprio povo e de sua cultura, em articulação com 
conhecimentos ocidentais; b) a existência dos conhecimentos ocidentais não necessariamente significa um processo de homogeneização. Para que não seja um processo de homogeneização, é fundamental que os conhecimentos sejam vistos como complementares, e náo como hierarquizados; c) apesar de toda a violência física e simbólica empreendida historicamente para impor um currículo e uma pedagogia colonial, baseiam-se na construçáo de pedagogias decoloniais que afirmam a cultura e a identidade indígena; c) apesar da tentativa de impor a epistemologia fascista como a única válida, continua existindo uma pluralidade epistêmica que, embora não seja reconhecida pelo fascismo epistemológico, responde melhor aos desafios desses povos; d) apesar dos mecanismos de controle e da negação histórica e sistemática das bases ancestrais espirituais dos povos indígenas, elas continuam presentes nas pedagogias decoloniais, mostrando outras possibilidades de estabelecer relaçóes com a natureza e de dar sentido à vida e ao mundo. De modo sintético, inspirando-nos em Walsh (2010), podemos afirmar que os indígenas, por meio da construção dos currículos e das pedagogias decoloniais, questionam a superioridade epistemológica, ontológico-existencial e cosmológica apregoada pelo euro-usa-centrismo.

\section{Consideraçóes finais}

Ao finalizar o artigo, lembramos Pinar (2007) quando afirma que as escolas, ao seguirem o currículo da lógica empresarial, não ensinam a eficácia prometida, mas inculcam a competição, o monoculturalismo eurocêntrico e a respeitabilidade burguesa.

Nesse sentido, pode-se dizer que os currículos das escolas indígenas são efetivamente um lócus de resistência, dado que se pautam em pedagogias decoloniais. Não há competição, mas colaboração entre comunidade e escola, entre alunos e professores. Não há monoculturalismo eurocêntrico, mas uma busca permanente da interculturalidade, marcada, sobretudo, não pela ideia de hierarquização, desqualificação e negação da diferença no modo de ser ou conhecer, mas pela possibilidade de conhecimentos diferentes serem complementares. Também não há 'respeitabilidade burguesa', pois com a pedagogia decolonial os indígenas mantêm a preocupação permanente de afirmação de sua cultura, identidade e modo de vida, e não 
se dobram nem à cultura burguesa nem ao seu modo de produção capitalista nem à pedagogia colonial.

Se a epistemologia fascista que sustenta a sociedade neoliberal quer convencer-nos de que, para os diferentes, desiguais, excluídos, discriminados, a soluçấo está em acessar os conhecimentos dos poderosos, com os indígenas aprendemos coisas muito mais interessantes: aprendemos a não nos dobrar aos poderosos (nem aos seus conhecimentos, nem à sua pedagogia); aprendemos a resistir; aprendemos a construir outros currículos, outras pedagogias. Aprendemos como construir pedagogias decoloniais.

\section{Referências}

ABBONIZIO, Aline; GHANEM, Elie. Educação escolar indígena e projetos comunitários de futuro. Educação e Pesquisa, São Paulo, USP, v. 42, n. 4, p. 887-90I, dez. 2016.

BAUMAN, Zygmunt. Comunidade: a busca por segurança no mundo atual. Rio de Janeiro: Jorge Zahar, 2003.

. Modernidade líquida. Rio de Janeiro: Jorge Zahar, $200 \mathrm{I}$.

BHABHA, Homi. O local da cultura. Belo Horizonte: UFMG, $200 \mathrm{I}$.

BACKES, José Licínio. A escola indígena intercultural: espaço/tempo de afi rmação da identidade étnica e de desconstrução da matriz colonial. Interaçôes, Campo Grande, UCDB, v. I5, n. I, p. I3-I9, jun. 2014.

; NASCIMENTO, Adir Casaro. Aprender a ouvir as vozes dos que vivem nas fronteiras étnico-culturais e da exclusão: um exercício cotidiano e decolonial. SérieEstudos, Campo Grande, UCDB, s.v, n. 3I, p. 25-34, jun. 201 I.

CAMARGO, Dulce Maria Pompêo de; ALBUQUERQUE, Judite Gonçalves de.

Projeto pedagógico xavante: tensōes e rupturas na intensidade da construção curricular. Cadernos Cedes, Campinas, UNICAMP, v. 23, n. 6I, p. 338-366, dez. 2003.

GOMES, Nilma Lino; JESUS, Rodrigo Ednilson de. As práticas pedagógicas de trabalho com relaçóes étnico-raciais na escola na perspectiva de Lei 10.639/2003: desafios para a política educacional e indagaçôes para a pesquisa. Educar em Revista, Curitiba, UFPR, s.v., n. 47, p.19-5I, mar. 2013.

HALL, Stuart. A centralidade da cultura: Notas sobre as revoluçóes culturais do nosso tempo. Educaçäo e Realidade, Porto Alegre, UFRGS, v. 22, n. 2, p. 15-46, dez. 1997.

Da diáspora: identidades e mediaçóes culturais. Belo Horizonte: UFMG, 2003.

HYPOLITO, Álvaro Moreira. Políticas curriculares, Estado e regulação. Educação \& Sociedade, Campinas, UNICAMP, v.3I, n.II3, p.I337-I354, dez. 2010.

LACLAU, Ernesto. Emancipação e diferença. Rio de Janeiro: Eduerj, 20 I I. 
MACEDO, Elizabeth. As demandas conservadoras do movimento Escola sem Partido e a Base Nacional Curricular Comum. Educação \& Sociedade, Campinas, UNICAMP, v. 38, n. I39, p.507-524, abr.-jun., 2017.

McLAREN, Peter. Multiculturalismo revolucionário: pedagogia do dissenso para o novo milênio. Porto Alegre: Artes Médicas, 2000.

PACHECO, José Augusto. Currículo, aprendizagem e avaliação. In: MORGADO, José Carlos; QUITEMBO, Alberto Domingos. Currículo, avaliação e inovaçâo em Angola: perspectivas e desafios. Benguela (Angola): Ondjiri, 20I4. p. 65-74.

PINAR, William. O que é a teoria do currículo. Porto (Portugal): Porto Editora. 2007. SANTOS, Boaventura de Sousa. A filosofia à venda, a douta ignorância e a aposta de Pascal. Revista de Ciências Sociais, Coimbra, Universidade de Coimbra, s.v., n. 8o, p. II-43, mar. 2008.

. Para além do pensamento abissal: das linhas globais a uma ecologia de saberes. Novos Estudos, São Paulo, CEPRAP, s.v., n. 79, p. 7I-94, 2007.

SKLIAR, Carlos. Pedagogia (improvável) da diferença: e se o outro não estivesse aí? Rio de Janeiro: DP\&A, 2003.

SOUSA, Edson Luiz André de. Entrevistar. In: FONSECA, Tania Mara Galli; NASCIMENTO, Maria Lívia; MARASCHIN, Cleci. Pesquisar na diferença: um abecedário. Porto Alegre: Sulina, 20I5. p. 87-88.

WALSH, Catherine. Estudios (inter)culturales en clave de-colonial. Revista Tábula Rasa, Bogotá, Universidad Colegio Mayor de Cundinamarca, s.v., n. I2, p. 209-227, jun. 2010. . Interculturalidade crítica e pedagogia decolonial: in-surgir, re-existir e

Recebido em 29 jan. 2018 / Aprovado em 20 mar. 2018

Para referenciar este texto

BACKES, J. L. A construção de pedagogias decoloniais nos currículos das escolas indígenas. EccoS - Revista Científica, São Paulo, n. 45, p. 4I-58. jan./abr. 2018. Disponível em: <https://doi.org/I0.5585/EccoS.n45.8290>. entre concepçóes, tensôes e propostas. Rio de Janeiro: 7 Letras, 2009. p. I2-43.

re-viver. In. CANDAU, Vera Maria (Org.). Educação intercultural na América Latina: 